\title{
Early filtration and mortality in meningococcal septic shock?
}

\author{
G Pearson, P C Khandelwal, N Naqvi
}

\begin{abstract}
Following the introduction of a policy of early therapeutic filtration for presumed meningococcal septicaemic shock, the overall mortality has decreased.

(Arch Dis Child 2000;83:508-509)
\end{abstract}

Keywords: meningococcal septicaemia; therapeutic filtration; septic shock

From 1995 to 1999 we pursued a policy of early therapeutic filtration for purpura fulminans with shock (presumed meningococcal septicaemia).

Patients with deteriorating blood pressure, accelerating tachycardia, or worsening acidosis despite aggressive resuscitation, received venovenous extracorporeal plasmafiltration, 1:1 exchanging 3-4 plasma volumes over four hours. After exchange, oliguric or anuric patients were supported with haemofiltration. Plasma exchange was repeated if clinical improvement was not observed or sustained.

In the three years prior to this policy, the crude mortality for meningococcal septicaemia on the paediatric intensive care unit (PICU) was $28 \%(n=60)$. During the 3.5 year period of the filtration policy, 101 children with meningococcal disease were admitted to the PICU. Eighty five patients were in shock. Of these, 62 were not filtered, of whom five died, including four patients with maximal Glasgow meningococcal septicaemia prognostic scores (GMSPS) who died within four hours of admission (negating any opportunity to complete a plasma exchange). Twenty three patients were filtered (six deaths). The overall mortality for meningococcal septic shock was $12.9 \%$.

Plasmafiltration was performed in 21 cases and haemofiltration alone in two. The mean time interval from the onset of symptoms to the start of filtration was 44.3 hours in the deaths whereas that in the survivors was 27.9 hours (difference between means 16.4 hours, standard error $7.07,95 \%$ confidence interval (CI) 1.69 to 31.1 ) Table 1 gives details of the filtration. The worst morbidity in the survivors occurred in those with the longest time interval between the onset of symptoms and commencing filtration.

The mortality for meningococcal disease ranges from $5 \%$ to $11 \%$ whereas that for associated septicaemic shock is $24-30 \%$. The historical mortality rate was comparable to those series. ${ }^{12}$ The mortality rate for meningococcal septicaemia may be falling; however, the UK Public Health Laboratory Service Communicable Disease Surveillance Centre 19921998 mortality rates for septicaemia (11-16\%)
Paediatric Intensive Care Unit, Birmingham Children's Hospital, Steelhouse Lane, Birmingham B4 6NH, UK

G Pearson

P C Khandelwal

N Naqvi

Correspondence to: Dr Pearson

gale.pearson@ bhamchildrens.wmids.nhs.uk

Accepted 13 July 2000

Table 1 Details relating to filtered patients

\begin{tabular}{|c|c|c|c|c|c|c|c|c|c|c|}
\hline Patient & $\begin{array}{l}\text { Age } \\
\text { (mth) }\end{array}$ & Sex & $\begin{array}{l}\text { Weight } \\
(\mathrm{kg})\end{array}$ & GMSPS & $\begin{array}{l}\text { Lead time } \\
\text { (h) }\end{array}$ & Filter & $\begin{array}{l}\text { Mean ultrafiltration } \\
\text { rate (plasma) } \\
(\mathrm{ml} / \mathrm{kg} / \mathrm{h})\end{array}$ & $\begin{array}{l}\text { Mean ultrafiltration } \\
\text { rate (haem) } \\
(\mathrm{ml} / \mathrm{kg} / \mathrm{h})\end{array}$ & $\begin{array}{l}\text { ICU } \\
\text { hours }\end{array}$ & $\begin{array}{l}\text { ICU } \\
\text { outcome }\end{array}$ \\
\hline 1 & 43 & M & 20 & 12 & 22 & $\mathrm{P}+\mathrm{H}$ & 19 & 22 & 527.50 & Survived \\
\hline 2 & 24 & M & 11 & 10 & 34 & $\mathrm{P}+\mathrm{H}$ & 23 & 45 & 121.50 & Survived \\
\hline 3 & 31 & $M$ & 15 & 12 & 24 & $\mathrm{P}$ & 10 & & 123.00 & Survived \\
\hline 4 & 4 & M & 6.4 & 9 & 45 & $\mathrm{H}$ & & 4 & 216.00 & Survived \\
\hline 5 & 1 & $M$ & 4 & 12 & 44 & $\mathrm{H}$ & & 23 & 44 & Died \\
\hline 6 & 14 & $\mathrm{~F}$ & 12 & 12 & 44 & $\mathrm{P}+\mathrm{H}$ & 42 & 11 & 115.42 & Survived \\
\hline 7 & 37 & $\mathrm{~F}$ & 15 & 8 & 31 & $\mathrm{P}+\mathrm{H}$ & 41 & 8 & 48.00 & Survived \\
\hline 8 & 5 & $\mathrm{~F}$ & 5 & 9 & 12 & $\mathrm{P}+\mathrm{H}$ & 30 & 50 & 258.25 & Survived \\
\hline 9 & 3 & M & 6 & 9 & 31 & $\mathrm{P}$ & 29 & & 66.75 & Survived \\
\hline 10 & 17 & $\mathrm{~F}$ & 12 & 10 & 24 & $\mathrm{P}$ & 8 & & 84.92 & Survived \\
\hline 11 & 15 & $\mathrm{~F}$ & 12 & 15 & 24 & $\mathrm{P}$ & 47 & & 119.25 & Survived \\
\hline 12 & 6 & M & 9.3 & 15 & 84 & $\mathrm{P}$ & 36 & & 26.75 & Died \\
\hline 13 & 5 & M & 5.5 & 14 & 24 & $\mathrm{P}+\mathrm{H}$ & 40 & 9 & 142.75 & Survived \\
\hline 14 & 4 & M & 5 & 15 & 56 & $\mathrm{P}+\mathrm{H}$ & 27 & 55 & 37.00 & Died \\
\hline 15 & 3 & $\mathrm{~F}$ & 5 & 15 & 24 & $\mathrm{P}$ & 52 & & 27.00 & Died \\
\hline 16 & 123 & M & 25 & 11 & 24 & $\mathrm{P}+\mathrm{H}$ & 41 & 7 & 142.75 & Survived \\
\hline 17 & 61 & M & 22.9 & 15 & 22 & $\mathrm{P}+\mathrm{H}$ & 11 & 7 & 132.33 & Survived \\
\hline 18 & 35 & $M$ & 15 & 7 & 24 & $\mathrm{P}$ & 34 & & 72.50 & Survived \\
\hline 19 & 22 & M & 12 & 15 & 20 & $\mathrm{P}+\mathrm{H}$ & 146 & 17 & 32.67 & Died \\
\hline 20 & 153 & $M$ & 27 & 15 & 53 & $\mathrm{P}+\mathrm{H}$ & 44 & 23 & 892.00 & Survived \\
\hline 21 & 11 & M & 10.1 & 13 & 24 & $\mathrm{P}+\mathrm{H}$ & 40 & 45 & 227.00 & Survived \\
\hline 22 & 21 & M & 12 & 15 & 38 & $\mathrm{P}+\mathrm{H}$ & 44 & 24 & 16.25 & Died \\
\hline 23 & 172 & $\mathrm{~F}$ & 60 & 14 & 12.5 & $\mathrm{P}+\mathrm{H}$ & 25 & 17 & 919.58 & Survived \\
\hline
\end{tabular}

P, plasma filtration; H, haemofiltration; ICU hours, length of ICU stay. 
are artificially low as a result of inclusion of patients without septicaemic shock but with positive blood cultures.

The GMSPS relating to the time of first contact between intensive care doctor and patient were worse for the shocked patients who were filtered. The difference between the mean scores was 4.7 points ( $95 \%$ CI 3.03 to 6.37 ) on a scale that ranges from 0 to 15 . A GMSPS score of 12 or above predicted mortality with $100 \%$ sensitivity but gave an expected mortality rate of $25 \%$. A maximal score of 15 however predicted death with a predictive power of 0.69 (negative predictive power 0.97 , sensitivity 0.82 , and specificity 0.94 ) irrespective of filtration. Experience of filtration in human meningococcal septic shock appears to mirror animal models with lower mortality than predicted in treated groups and reduced or no effect if plasma exchange is delayed.

The low mortality (44\% of predicted) associated with an intention to treat with filtration could be a result of confounding factors. However, we suggest a causal relation. A randomised controlled trial involving 244 patients could detect an effect size as large as implied with an alpha of $<0.05$ and a beta of $<0.05$. $^{3}$

1 Kornelisse RF, Hazelzet JA, Hop WC, et al. Meningococcal septic shock in children: clinical and laboratory features, outcome, and development of a prognostic score. Clin Infect Dis 1997;25:640-6.

2 Riordan FA, Marzouk O, Thomson AP, Sills JA, Hart CA. The changing presentations of meningococcal disease. Eur f Pediatr 1995;154:472-4.

3 PC SIZE: A program for sample size determinations [computer program]. The American Statistician, 40, 52, 1986.

\section{Congenital anomalies around the world}

Data about congenital anomalies over the last five decades have been reported to the World Health Organisation from 36 countries in Europe, North and South America, Asia (Japan), and Australasia (Aldo Rosano and colleagues. Fournal of Epidemiology and Community Health 2000;54:660-6).

In 1950-54, congenital anomalies were the cause of $9 \%$ of a total infant mortality rate of around 400 per 10000 live births in these countries. By 1990-94, total infant mortality rate was around 120 per 10000 and congenital anomalies caused $20 \%$ of these deaths. In the United Kingdom, congenital anomalies caused $16 \%$ of infant deaths (45.8 deaths from congenital anomalies per 10000 live births) in 1950-54 and $21 \%$ (14.4 per 10000 live births) in 1990-94. In 199094, the UK had the lowest rate of the 36 countries apart from France (13.7 per 10000 live births). High rates were observed in South and central America, Greece, and some countries of eastern Europe. Overall, deaths from congenital anomalies decreased by a third over the study period although there have been recent increases in central and Latin America and eastern Europe. Compared with poorer countries, wealthy countries have fewer infant deaths from congenital anomalies but such deaths make up a greater proportion of total infant mortality. For example, in 1990-94, Sweden's infant mortality from congenital anomalies was 19.2 per 10000 live births (35\% of total infant mortality) whereas in Uruguay the rate was 36.3 per 10000 live births (18\% of total). Anomalies of the heart and central nervous system account for almost half of all infant deaths due to congenital anomalies.

ARCHIVIST 